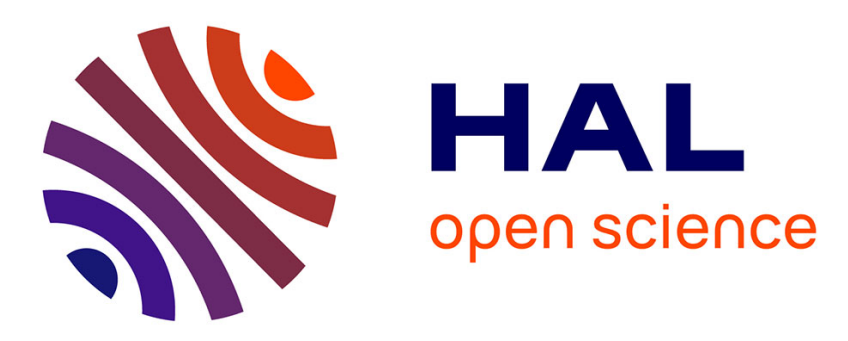

\title{
Monitoring hydrodynamic effects in helium atmospheric pressure plasma jet by resonance broadening emission line
}

\author{
Sylvain Iséni, Cécile Pichard, Ahmed Khacef
}

\section{- To cite this version:}

Sylvain Iséni, Cécile Pichard, Ahmed Khacef. Monitoring hydrodynamic effects in helium atmospheric pressure plasma jet by resonance broadening emission line. Applied Physics Letters, 2019, 115 (3), pp.034102. 10.1063/1.5110714 . hal-02187494

\section{HAL Id: hal-02187494 \\ https://hal.science/hal-02187494}

Submitted on 17 Jul 2019

HAL is a multi-disciplinary open access archive for the deposit and dissemination of scientific research documents, whether they are published or not. The documents may come from teaching and research institutions in France or abroad, or from public or private research centers.
L'archive ouverte pluridisciplinaire HAL, est destinée au dépôt et à la diffusion de documents scientifiques de niveau recherche, publiés ou non, émanant des établissements d'enseignement et de recherche français ou étrangers, des laboratoires publics ou privés. 


\title{
Monitoring hydrodynamic effects in helium atmospheric pressure plasma jet by resonance broadening emission line
}

\author{
S. Iseni, ${ }^{1,}$ a) C. Pichard, ${ }^{2}$ and A. Khacef ${ }^{1}$ \\ ${ }^{1)}$ GREMI (Groupe de Recherches sur l'Énergétique des Milieux Ionisés) - UMR7344 CNRS / Université d'Orléans, \\ 14 rue d'Issoudun, 45067 Orléans, France. \\ ${ }^{2)}$ Polytech Orléans, Université d'Orléans, Site Galilée, 12 rue de Blois, 45067 Orléans, \\ France.
}

(Dated: July 14, 2019)

Atmospheric pressure plasma jet (APPJ) producing guided ionization wave (IW) in helium (He) is investigated by optical emission spectroscopy (OES) with regard to the hydrodynamics, i.e. helium-air mixing and the buoyancy force. A non-invasive method based on the analysis of the resonant broadening line profile is introduced to diagnose the action of the IW on the He laminar flow. The total force acting upon the gas flow (summarizing the electohydrodynamic (EHD) force and the buoyancy force $\left(\mathbf{f}_{b}\right)$ ) is investigated experimentally. Quantitative results are in agreement with published data obtained by numerical modeling. Furthermore, low content of air fraction diffusing into the He flow can be determined from the resonant broadening line profile. The latter is of high interest in biomedical and agriculture applications as well as material surface and liquid activation.

doi:10.1063/1.5110714

Atmospheric pressure plasma jet devices ${ }^{1}$ (APPJ) generating guided ionization waves ${ }^{2}$ (IW) have become an inescapable tool in the development of modern plasma processes. Due to the specificity of room temperature plasma, the application pool is perpetually growing in the fields of nano and micro material processing ${ }^{3,4}$, liquid activation ${ }^{5}$, active flow control ${ }^{6}$ and environment ${ }^{7,8}$. APPJ are also involved in societal challenges as an innovative medical approach to activate healing biological mechanisms ${ }^{9}$ and as a promising cancer therapy ${ }^{10}$. Lately, APPJ have also demonstrated their potential in agriculture $^{11,12}$ and in the food industry ${ }^{13}$.

The APPJ offer the advantages of a simple design, a cheap construction and the flexibility to integrate into industrial processes. The propagation of guided IW guided streamer ${ }^{14}$ - yields a single partially ionized channel from a dielectric tube ${ }^{15}$. The uniqueness of nonequilibrium plasma combining different forms of energy electric, ionization, chemical, radiant and thermal - leads to the effective production of reactive oxygen and nitrogen species (RONS) with air mixture. Fluid dynamics is also an important aspect to consider in atmospheric pressure plasma sources. This is particularly true for gliding-arcs ${ }^{16}$ where the gas flow governs the motion of the ionized volume, in comparison with plasma guns displacement induced by the electromagnetic force ${ }^{17}$. Hydrodynamics plays a crucial role in APPJ, particularly on the propagation length of the IW out of the tube ${ }^{18}$. Several works involving imaging techniques have qualitatively reveled the plasma action on the He gas flow, showing transitions from laminar to turbulent regime ${ }^{19,20}$. Hydrodynamics of APPJ is by far the least understood macroscopic aspect of the discharge while it is essential

\footnotetext{
a) sylvain.iseni@univ-orleans.fr
}

to control the mixing of the air into the rare gas -in presence of IW- for its critical consequence for the RONS production $^{21,22}$. Currently, clarifications about flow modifications due to gas heating and/or electrohydrodynamic (EHD) forces are considered as an ongoing discussion in the community ${ }^{23}$.

This investigation is devoted to present an original approach to diagnose the hydrodynamics of guided IW in He interacting with the ambient air. Due to the reactivity of the plasma, hydrodynamic diagnostics are rather limited to imaging techniques. Schlieren imaging are typically used as a qualitative technique for flow pattern visualization. Pseudo-quantitative air fraction mixed in rare gas was carried out with planar laser-induced fluorescence $^{24}$ or Rayleigh scattering ${ }^{23}$. Recently, a minimally intrusive technique for relative quantitative analysis of plasma action on gas flow has been developed using a homemade sensitive manometer ${ }^{25}$.

The idea of this study follows the spirit of previous published works ${ }^{26,27}$ where OES was used to reliably measure the absolute electric field of IW and the gas temperature in APPJ. The motivation is to develop an OES technique as a remote, simple to implement, space and time resolved method to characterize the plasma flow action by means of intrinsic atomic line resonance broadening. A particular attention will be paid to the buoyancy force $\left(\mathbf{f}_{b}\right)$ as part of the hydrodynamics of the IW.

The APPJ used in this work is a typical coaxial dielectric barrier discharge-like (DBD) configuration ${ }^{1}$ (see Fig. 1). It consists of a $100 \mathrm{~mm}$ long glass tube of $4.0 \mathrm{~mm}$ inner diameter. The He gas (Alphagaz 2, Air Liquide) flows into the tube at a flow rate of $500 \mathrm{sccm}$ before to mix with the ambient air. The flow pattern is laminar. A tungsten needle of $0.5 \mathrm{~mm}$ diameter is located within the tube along its axis and the grounded ring electrode is wrapped around the outer tube surface. The needle is connected to a high voltage (HV) generator (nanogen3, RLC Elec- 


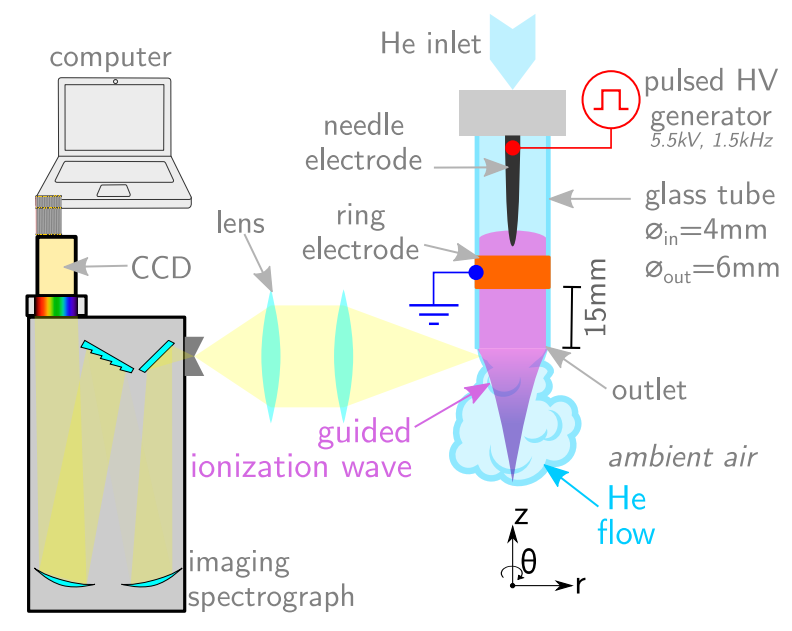

Figure 1. Schematics of the experimental setup. Left: optical emission spectroscopic imaging system. Right: configuration of the APPJ device generating guided IW.

tronic) delivering positive square pulses of $5.5 \mathrm{kV}$ amplitude at $1.5 \mathrm{kHz}$. The pulse width is $1.0 \mu$ s with a rise/fall time of $102 \mathrm{~ns}$. Each HV excitation ignites a breakdown leading to the generation of a guided IW which propagates through the tube until it expands into free-space and interacts with the ambient $\mathrm{air}^{2}$. In these conditions, the current peak reaches $0.9 \mathrm{~A}$ as also documented in ${ }^{15,23}$. The OES diagnostic is performed with a $0.75 \mathrm{~m}$ focal length imaging spectrograph (SP2750, Princeton Instruments) with a standard configuration (1800 grooves $/ \mathrm{mm}$ diffraction grating). The diffracting image is recorded with a CCD camera (PIXIs:256, $1024 \times 256$ pixels, Princeton Instruments). As shown in Fig. 1, a doublet of aspheric lenses (0.5 magnification) focuses the emission of the IW on the $30 \mu \mathrm{m}$ entrance slit of the spectrograph. To optimize the signal-to-noise ratio of the spectra, the image is averaged over 9 to 25 accumulations, each of $10 \mathrm{~s}$ exposure time.

OES methods are often based on line profiles analysis which requires precise knowledge on the broadening mechanisms. Apart from the broadening induced by the instrumental function, spectral line shapes result from tangled interactions inherent to the ionized gas ${ }^{28}$. While the natural, the Doppler $\left(w_{\mathrm{D}}\right)$, the Stark $\left(w_{\mathrm{S}}\right)$ and the van der Waals broadening $\left(w_{\mathrm{vdw}}\right)$-and sometime shiftmechanisms apply to any atomic radiative transition, the resonance broadening occurs for transitions involving a level that is dipole-coupled to ground state. A comprehensive formalism of each broadening can be found in the monograph of H. R. Griem ${ }^{28}$ or more pragmatically in the review of Djurović and Konjević ${ }^{29}$. The FWHM of the resonance broadening, $w_{\mathrm{R}}$, can be expressed as,

$$
w_{\mathrm{R}}=K(0,1) \frac{r_{\mathrm{e}}}{\pi} \lambda_{\mathrm{R}} f_{\mathrm{R}} \sqrt{\frac{g_{\mathrm{G}}}{g_{\mathrm{R}}}} \lambda_{0}^{2} N_{\mathrm{R}}
$$

where $r_{\mathrm{e}}$ is the classical electron radius, $g_{\mathrm{G}}$ and $g_{\mathrm{R}}$ are the statistical weights of the ground and the resonant state, respectively. $f_{\mathrm{R}}$ is the oscillator strength of the resonance transition of wavelength $\lambda_{R}$ and $K(0,1)$ is related to the total angular momenta of the ground and the resonant states. $\lambda_{0}$ is the central wavelength of one of the lines affected by the resonance and $N_{\mathrm{R}}$ the ground state density. In $\mathrm{He}$, all the transitions involving the resonance state $2 \mathrm{p}^{1} \mathrm{P}_{1}\left(\lambda_{\mathrm{R}}\right)$ are dipole-coupled to the ground state that produces a significant broadening to these lines ${ }^{30}$.

In this work, the resonance transition of $\mathrm{He}\left(3 \mathrm{~s}^{1} \mathrm{~S}_{0} \rightarrow 2 \mathrm{p}^{1} \mathrm{P}_{1}\right) \quad$ emitting at $\lambda_{0}=728.135 \mathrm{~nm}$ is considered. This transition offers several advantages: a reasonable intensity, a clear separation with the neighbor spectral bands of $\mathrm{N}_{2}$ (B-A) -first positive system- and a stronger resonance broadening compared to other lines. In addition, Malvern et. al. ${ }^{30}$ concluded that in this type of emission experiments, it is the only strongly resonance-broadened $\mathrm{He}$ line for which a quantitative interpretation is possible. The $\mathrm{FWHM}^{31}$ of each broad-

Table I. Calculated FWHM $\left(w_{-}\right)$of each broadening mechanism contributing to the line shape of the He transition $\left(3 \mathrm{~s}^{1} \mathrm{~S}_{0} \rightarrow 2 \mathrm{p}^{1} \mathrm{P}_{1}\right)$ are determined according to Djurović and Konjević $^{29}$ assuming $T_{\mathrm{g}}=320 \mathrm{~K}$ at $1013 \mathrm{hPa}$. (unit: $10^{-3} \mathrm{~nm}$ )

\begin{tabular}{cccc|cc}
\hline \hline \multicolumn{4}{c|}{ Lorentzian profile } & \multicolumn{2}{c}{ Gaussian profile } \\
$w_{\text {natural }}$ & $w_{\mathrm{S}}$ & $w_{\mathrm{vdw}}$ & $w_{\mathrm{R}}$ & $w_{\mathrm{D}}$ & $\bar{w}_{\text {inst. }}$ \\
\hline $0.5 \pm 0.2$ & $0.6 \pm 0.2^{\mathrm{a}}$ & $42 \pm 5$ & $94 \pm 4$ & $4.4 \pm 0.1$ & $25 \pm 1$ \\
\hline \hline \multirow{3}{*}{ alculated for an electron temperature $T_{\mathrm{e}}=2 \mathrm{eV}$ and a } \\
maximum electron density $n_{\mathrm{e}}=10^{14} / \mathrm{cm}^{3}$.
\end{tabular}

ening mechanism contributing to the profile of the $\mathrm{He}$ line at $728.135 \mathrm{~nm}$ are calculated for the experimental conditions of this study and presented in Table I.

Often, the recorded spectral line shape is a convolution between several broadening profiles being either Lorentzian or Gaussian resulting in a Voigt distribution. An example of the investigated $\mathrm{He}$ line profile originating from the guided IW is presented in Fig. 2. The recorded line is compared to the measured instrumental profile. The line shapes are analyzed by fitting a Voigt distribution to the experimental data. The numerical realization of the Voigt fit is performed by computing the real part of the Faddeeva function. The advantage is twofold: to determine accurately $w_{\mathrm{L}}$ and $w_{\mathrm{G}}$, the respectively FWHM of the Lorentzian and the Gaussian contributions to the Voigt width; to perform an implicit deconvolution of the Lorentzian dominated line profile with the Gaussian dominated instrumental function. Fig. 3 shows the relative variation of the instrumental profile $\left(\delta_{\mathrm{FWHM}}\right)$ along the entrance slit and the Gaussian fraction. Indeed, the spectrometer exhibits a quasi-constant Gaussian profile with remarkably low values of $\delta_{\text {FWHM }}$ centered around $\bar{w}_{\text {inst. }}=25.0 \mathrm{pm}$. Due to the distributivity property of the convolution, the experimental quantification of the line profile variation is directly related to $\delta_{\text {FWHM }}$. Practically, the detection limit to measure the variation of $w_{\mathrm{L}}$ is limited to 


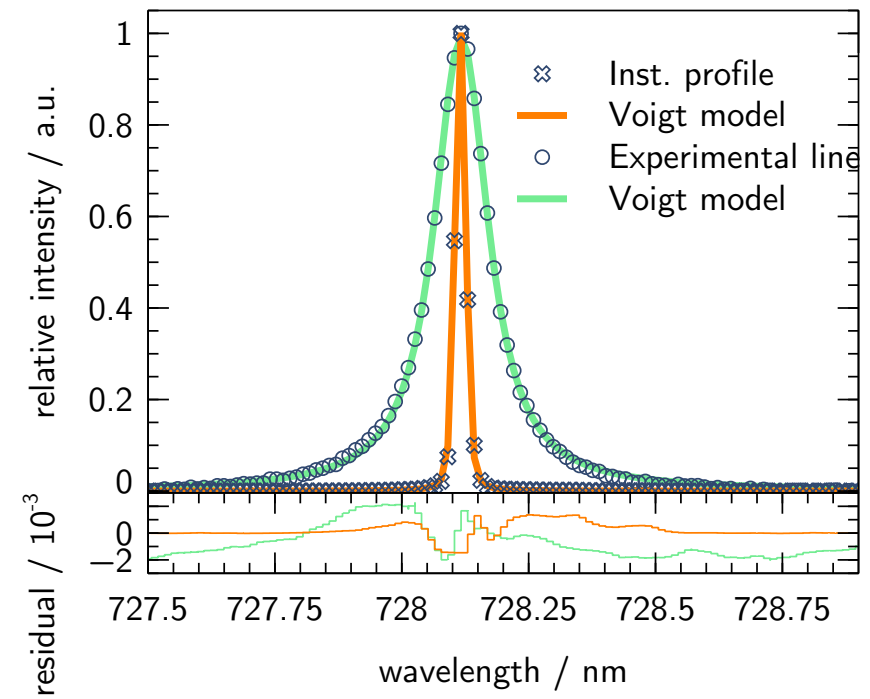

Figure 2. Recorded line shapes of the He transition $\left(3 \mathrm{~s}^{1} \mathrm{~S}_{0} \rightarrow 2 \mathrm{p}^{1} \mathrm{P}_{1}\right)$. The instrumental profile is measured using a narrow line from a Geissler tube and fits a Voigt model with a FWHM of $\bar{w}_{\text {inst. }}=25.0$ pm (Gaussian fraction: $86 \%$ ). Typical investigated line shape originating from the IW within the tube is shown and fits a Voigt model. The residuals of both fits are documented to support the analysis of the profiles.

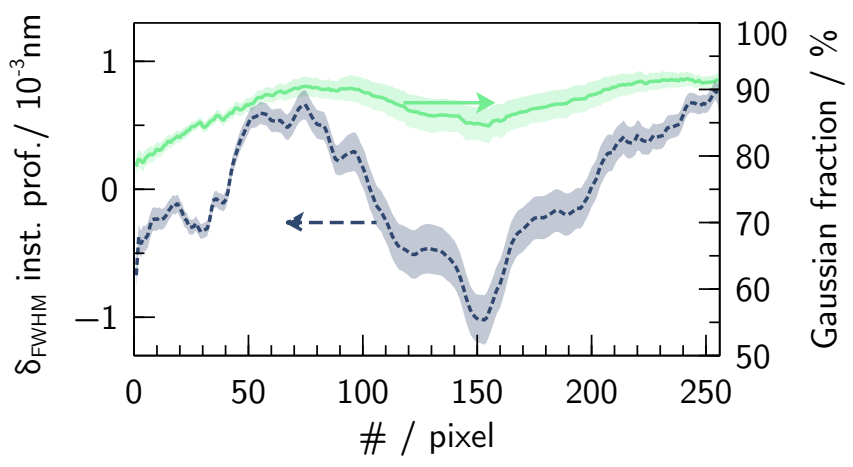

Figure 3. Deviation $\left(\delta_{\mathrm{FWHM}}=w_{\#}-\bar{w}_{\text {inst. }}\right)$ of the instrumental profile along the entrance slit (CCD column) of the spectrometer. The Gaussian fraction corresponds to the relative contribution to the Voigt profile fitting the instrumental function. The uncertainties are taken as the standard deviation (shaded area).

$2 \times \delta_{\mathrm{FWHM}}$, i.e. $\sim 2 \mathrm{pm}$.

According to Table I, one can reasonably assume $w_{\mathrm{L}} \approx w_{\mathrm{R}}+w_{\mathrm{vdw}}$. Considering Eq. (1) and the van der Waals broadening described $i^{28,29}$, one finds the following proportionality,

$$
w_{\mathrm{L}} \propto T_{\mathrm{g}} \cdot n_{\mathrm{He}},
$$

with $n_{\mathrm{He}}$ the number density of He atoms in the ground state. Interestingly, the conditions of low temperature atmospheric pressure plasmas are in favor of enhancing the resonant broadening of the line while other broadening mechanisms remain in the same order or reduce. In the following one will study the contribution of the buoyancy force on $w_{\mathrm{L}}$ with respect to the orientation of the APPJ set either downward or upward. Fig. 4 shows the emission intensity along the tube axis corresponding to the propagation length of the guided IW. The inten-

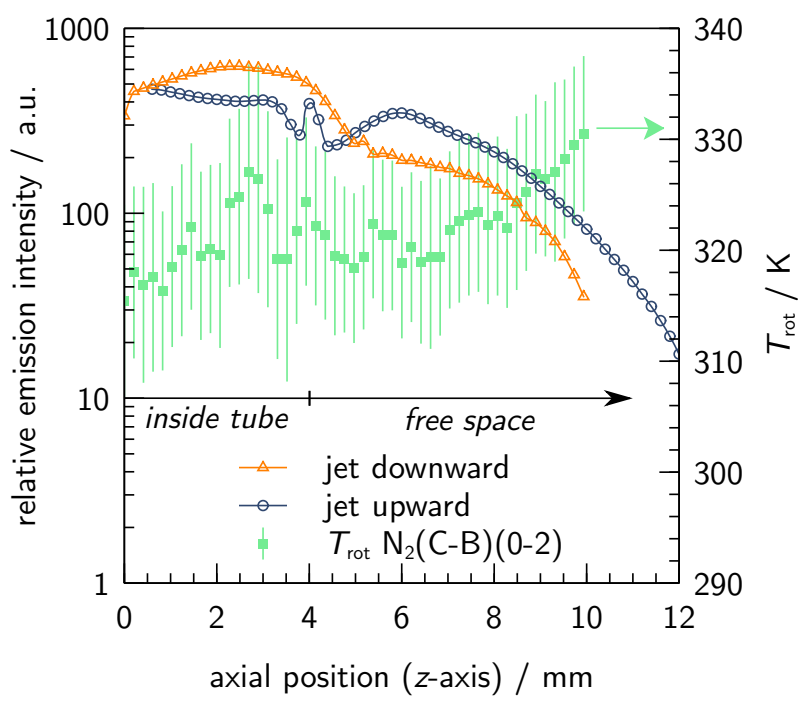

Figure 4. Relative emission intensity of the He $728.135 \mathrm{~nm}$ line along the axis of the tube. The APPJ is set vertically with the He gas flowing downward or upward. $T_{\text {rot }}$ of $\mathrm{N}_{2}(\mathrm{C}-$ B) are measured along the axis. Uncertainties correspond to the computed $95 \%$ confidence interval. The outlet of the tube is at $4.0 \mathrm{~mm}$.

sity is constant within the tube and starts to decrease outside -independently of the APPJ direction- once the He flow interacts with the air. However, the propagation length is about $2 \mathrm{~mm}$ longer for the APPJ set upward. $T_{\mathrm{g}}$ is determined via $T_{\text {rot }}$ assuming the rotational population distributions of $\mathrm{N}_{2}(\mathrm{C}-\mathrm{B})$ in equilibrium ${ }^{32}$. In total agreement with Doremaele et. al. ${ }^{23}, T_{\mathrm{g}}$ is found to be constant along the IW propagation. Thus $w_{\mathrm{L}}$ becomes directly proportional to $n_{\mathrm{He}}$.

The longitudinal spatial evolution of $w_{\mathrm{L}}$ along the APPJ directed downward is presented in Fig. 5. The first $4 \mathrm{~mm}$ corresponds to the emission from the IW propagating through the tube filled with He (carrier pipe impurities $\left.<10^{13} / \mathrm{cm}^{3}\right)$. Constant $T_{\mathrm{g}}$ implies a noticeable uniform values of $w_{\mathrm{L}}$ inside the tube. At $z=4 \mathrm{~mm}$, the IW leaves the guidance of the tube to propagate through the $\mathrm{He}$ channel expanding into the air. A steep rise of $w_{\mathrm{L}}$ is observed in the first $\mathrm{mm}$ outside the tube (from $4 \mathrm{~mm}$ to $5 \mathrm{~mm}$ ). The sharp rise of $w_{\mathrm{L}}$ results from a higher $n_{\mathrm{He}}$ value than within the tube, e.g. a rise of the He partial pressure $\left(p_{\mathrm{He}}\right)$. The link with the EHD force is given according to,

$$
\frac{\Delta p_{\mathrm{He}}}{\Delta z}=\frac{1}{S} \cdot \frac{\Delta \mathbf{f}}{\Delta z},
$$

with $\Delta p_{\mathrm{He}} / \Delta z$ the pressure gradient along the z-axis, $\Delta \mathbf{f} / \Delta z$ the force gradient applied to a surface $S$. This leads to estimate the EHD force per unit volume $\left(\mathrm{N} / \mathrm{m}^{3}\right)$. The rise of $w_{\mathrm{L}}$ for different radial positions evidences 


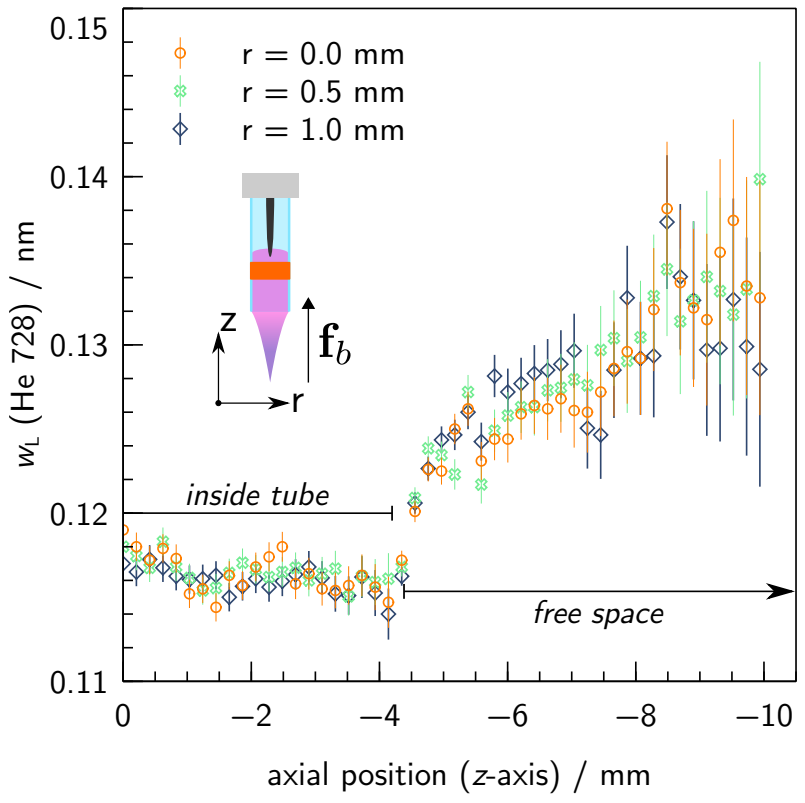

Figure 5. Lorentzian width $\left(w_{\mathrm{L}}\right)$ of the He $728.135 \mathrm{~nm}$ line along the guided IW propagation for three radial positions. The APPJ is set downward (against the buoyancy force, $\mathbf{f}_{b}$ ). The outlet of the tube is at $4.0 \mathrm{~mm}$.

the action of the IW on the hydrodynamics (EHD force) which is sustained all along the propagation (over $\sim 6 \mathrm{~mm}$, cf. Fig. 4). Apart from the larger uncertainties at the end of the IW path which are due to a weaker emission signal, $w_{\mathrm{L}}$ increases constantly. This means that $p_{\mathrm{He}}$ increases monotonically on the longitudinal direction and uniformly on the radial direction to structure the $\mathrm{He}$ channel against $\mathbf{f}_{b}$. Cross section observations confirmed that radial positions off axis do not require the reconstruction of light source distributions from intensities under the present conditions. It is important to note that the air mixing with the He flow will reduce $p_{\mathrm{He}}$ and thus $w_{\mathrm{L}}$. Interestingly, $w_{\mathrm{L}}$ curve does not show any change of the trend while the air fraction is expected to increase as further away from the tube outlet. This means that with the APPJ set downward, $w_{\mathrm{L}}$ is more sensitive to the effect of the EHD force (via $p_{\mathrm{He}}$ ) than to the air diffusion into the He channel.

Intuitively, by flipping over vertically the APPJ, the He flow and the IW will develop upward in the same direction as the buoyancy force. The analysis of $w_{\mathrm{L}}$ on the longitudinal direction and for different radial positions are presented in Fig. 6 . In agreement with the previous condition (APPJ sets downward), $w_{\mathrm{L}}$ values are constant and remain unchanged within the tube, independently on the radial position. This is expected since the $\mathrm{He}$ flow and the IW are both guided by the tube wall. However, drastic changes of the $w_{\mathrm{L}}$ curves are observed once the IW propagates outside the tube $(z=4 \mathrm{~mm})$ revealing significant influences on the hydrodynamics. Indeed, $w_{\mathrm{L}}$ are monotonically decreasing throughout the IW development while no steep rise is observed within the first

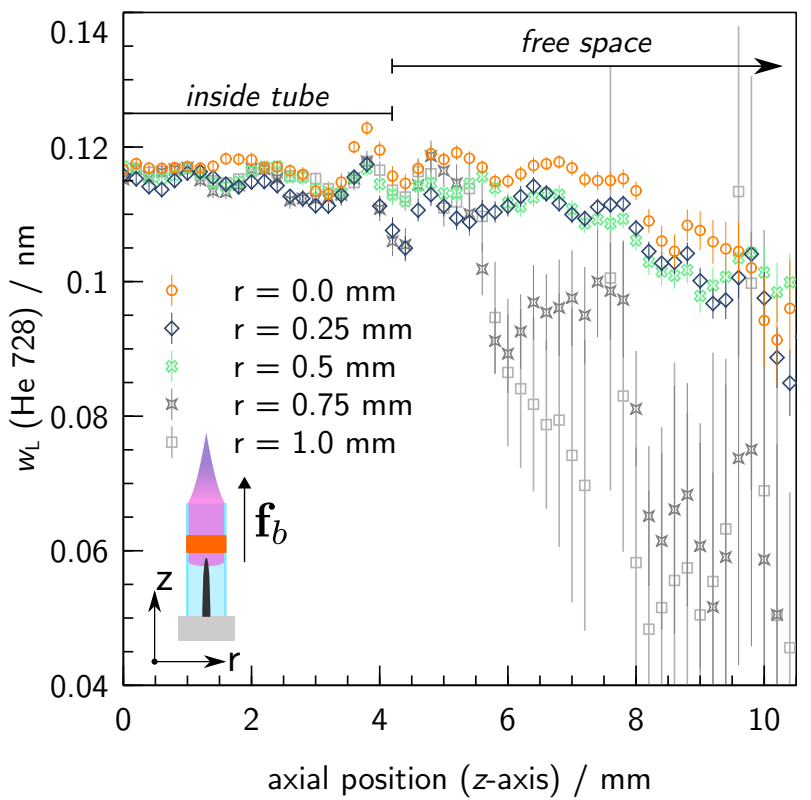

Figure 6. Lorentzian width $\left(w_{\mathrm{L}}\right)$ of the He $728.135 \mathrm{~nm}$ line along the guided IW propagation for five radial positions. The APPJ is set upward. The outlet of the tube is at $4.0 \mathrm{~mm}$.

$\mathrm{mm}$ of the outer He flow. Variations of $w_{\mathrm{L}}$ along the radial direction is clearly visible with the APPJ set upward. $w_{\mathrm{L}}$ curves at $r=0.75 \mathrm{~mm}$ and $r=1.0 \mathrm{~mm}$ experience of clear drop and large uncertainties due to the weak emission of the IW. These facts are explained by the diffusion of air into the He flow happening closer to the tube outlet than in the previous case (cf. APPJ downward) where the EHD force plays against $\mathbf{f}_{b}$. The pure He channel is shrinking by the air fraction diffusing throughout the development of the He flow from which results a confining of the IW to propagate along the tube axis. The IW development sustains as long as the ionization rate of the gas mixture remains sufficient with regards to the electric field ${ }^{14,33}$. In addition, having $\mathbf{f}_{b}$ in the same direction as the He flow enhances the stability of the flow which leads to a longer IW propagation than in the APPJ set downward (cf. Fig. 4). The gradient of mixing air is revealed with the diminution of $w_{\mathrm{L}}$ along the tube axis for radial position ranging from $0 \mathrm{~mm}$ to $0.5 \mathrm{~mm}$. It is possible to determine the air density from the depletion of $n_{\mathrm{He}}$ (decrease of $w_{\mathrm{L}}$ ). Considering $w_{\mathrm{L}}$ value inside the tube as the reference for pure He conditions $(0.116 \pm 0.002 \mathrm{~nm})$, the air fraction at the end of the IW propagation $(z=10 \mathrm{~mm}$, $\left.w_{\mathrm{L}}=0.097 \pm 0.002 \mathrm{~nm}\right)$ is estimated to be $16 \pm 5 \%$. This value is in total agreement with previous theoretical and experimental studies ${ }^{23,33,34}$.

Estimations of the EHD force per unit volume can be carried out from Eq. (3) and the measurements shown in Fig. 5. In case of downward directed APPJ, the air fraction can be reasonably neglected in the vicinity of the tube outlet. As previously, considering the pressure within the tube as a reference value for $w_{\mathrm{L}}$, the rise of $p_{\mathrm{He}}$ within the first $\mathrm{mm}$ is estimated from $3 \mathrm{kPa}$ 
to $6 \mathrm{kPa}$. Thus the resulting average EHD force would range from $3 \times 10^{6} \mathrm{~N} / \mathrm{m}^{3}$ to $6 \times 10^{6} \mathrm{~N} / \mathrm{m}^{3}$. The present values of EHD are consistent with data found in the literature for cold atmospheric pressure plasmas ${ }^{35,36}$ and recent computational results of guided IW in He APPJ $\left(\sim 2.3 \times 10^{6} \mathrm{~N} / \mathrm{m}^{3}\right)^{37}$.

To conclude, this letter reports on the development of a successful non-intrusive method based on resonant broadening line profile to study hydrodynamic parameters of guided IW generated by APPJ. A comprehensive description of the technique is presented focusing on its simplicity to be applied to APPJ in He at atmospheric pressure. The resonance transition of $\mathrm{He}\left(3 \mathrm{~s}^{1} \mathrm{~S}_{0} \rightarrow 2 \mathrm{p}^{1} \mathrm{P}_{1}\right)$ emitting at $\lambda_{0}=728.135 \mathrm{~nm}$ is analyzed to infer the density of $\mathrm{He}$ in the ground state. The Lorentzian contribution to the FWHM of the latter line shape appears to significantly vary depending on the APPJ operation direction, allowing for estimating the IW action on the hydrodynamics of the gas flow. Thus the total force acting upon the gas flow (with the EHD force against the buoyancy force) can be experimentally estimated to range from $3 \times 10^{6} \mathrm{~N} / \mathrm{m}^{3}$ to $6 \times 10^{6} \mathrm{~N} / \mathrm{m}^{3}$ showing remarkable agreements with simulation results from the literature. Setting the APPJ upward allows us to determine the low content air fraction diffusing into the He channel guiding the IW propagation. Accordingly, the newly developed method can be easily implemented in real applications of APPJ especially in the field of plasma-liquid activation, plasma medicine as well as material and environmental science.

\section{ACKNOWLEDGMENTS}

This work originates from the cooperative project plasma- $\pi$ VII. SI would like to thank Professor Nelly Bonifaci for the fruitful discussions about resonant lines and her continuous encouragement.

\section{REFERENCES}

${ }^{1}$ X. Lu, M. Laroussi, and V. Puech, Plasma Sources Science and Technology 21, 034005 (2012).

${ }^{2}$ X. Lu and K. K. Ostrikov, Applied Physics Reviews 5, 031102 (2018).

${ }^{3}$ Y. Kusano, The Journal of Adhesion 90, 755 (2014).

${ }^{4}$ M. Šimek, M. Černák, O. Kylián, R. Foest, D. Hegemann, and R. Martini, Plasma Processes and Polymers 16, 1700250 (2019). ${ }^{5}$ P. J. Bruggeman, M. J. Kushner, B. R. Locke, J. G. E. Gardeniers, W. G. Graham, D. B. Graves, R. C. H. M. Hofman-Caris, D Maric, J. P. Reid, E. Ceriani, D. F. Rivas, J. E. Foster, S. C. Garrick, Y. Gorbanev, S. Hamaguchi, F. Iza, H Jablonowski, E. Klimova, J. Kolb, F. Krcma, P. Lukes, Z. Machala, I. Marinov, D. Mariotti, S. M. Thagard, D Minakata, E. C. Neyts, J. Pawlat, Z. L. Petrovic, R. Pflieger, S. Reuter, D. C. Schram, S. Schröter, M. Shiraiwa, B Tarabová, P. A. Tsai, J. R. R. Verlet, T. von Woedtke, K. R. Wilson, K. Yasui, and G. Zvereva, Plasma Sources Science and Technology 25, 053002 (2016).

${ }^{6}$ E. Moreau, Journal of Physics D: Applied Physics 40, 605 (2007). ${ }^{7}$ R. Brandenburg, A. Bogaerts, W. Bongers, A. Fridman, G. Fridman, B. R. Locke, V. Miller, S. Reuter, M. Schiorlin, T. Verr- eycken, and K. K. Ostrikov, Plasma Processes and Polymers 16, 1700238 (2019).

${ }^{8}$ B. M. Obradović, G. B. Sretenović, and M. M. Kuraica, Journal of Hazardous Materials 185, 1280 (2011).

${ }^{9}$ J.-S. Oh, X. Strudwick, R. D. Short, K. Ogawa, A. Hatta, H. Furuta, N. Gaur, S.-H. Hong, A. J. Cowin, H. Fukuhara, K. Inoue, M. Ito, C. Charles, R. W. Boswell, J. W. Bradley, D. B. Graves, and E. J. Szili, Applied Physics Letters 109, 203701 (2016).

${ }^{10}$ D. Yan, W. Xu, X. Yao, L. Lin, J. H. Sherman, and M. Keidar, Scientific Reports 8, 15418 (2018).

${ }^{11}$ X. Zhang, D. Liu, R. Zhou, Y. Song, Y. Sun, Q. Zhang, J. Niu, H. Fan, and S.-z. Yang, Applied Physics Letters 104, 043702 (2014).

${ }^{12}$ L. Sivachandiran and A. Khacef, RSC Advances 7, 1822 (2017).

${ }^{13}$ F.-G. Chizoba Ekezie, D.-W. Sun, and J.-H. Cheng, Trends in Food Science \& Technology 69, 46 (2017).

${ }^{14}$ J.-P. Boeuf, L. L. Yang, and L. C. Pitchford, Journal of Physics D: Applied Physics 46, 015201 (2013).

${ }^{15}$ M. Rong, W. Xia, X. Wang, Z. Liu, D. Liu, Z. Liang, X. Zhang, and M. G. Kong, Applied Physics Letters 111, 074104 (2017).

${ }^{16}$ A. Fridman, S. Nester, L. A. Kennedy, A. Saveliev, and O. MutafYardimci, Progress in Energy and Combustion Science 25, 211 (1999).

${ }^{17}$ K. Thom, J. Norwood, and N. Jalufka, The Physics of Fluids 7, S67 (1964).

${ }^{18}$ Q. Li, J.-T. Li, W.-C. Zhu, X.-M. Zhu, and Y.-K. Pu, Applied Physics Letters 95, 141502 (2009).

${ }^{19}$ M. H. Qaisrani, Y. Xian, C. Li, X. Pei, M. Ghasemi, and X. Lu, Physics of Plasmas 23, 063523 (2016).

${ }^{20}$ A. Sobota, O. Guaitella, G. B. Sretenović, I. B. Krstić, V. V. Kovačević, A. Obrusník, Y. N. Nguyen, L. Zajíčková, B. M. Obradović, and M. M. Kuraica, Plasma Sources Science and Technology 25, 065026 (2016).

${ }^{21}$ S. Iseni, S. Zhang, A. F. H. van Gessel, S. Hofmann, B. T. J. van Ham, S. Reuter, K.-D. K.-D. Weltmann, and P. J. Bruggeman, New Journal of Physics 16, 123011 (2014).

${ }^{22}$ A. M. Lietz, E. Johnsen, and M. J. Kushner, Applied Physics Letters 111, 114101 (2017).

${ }^{23}$ E. R. W. V. Doremaele, V. S. S. K. Kondeti, and P. J. Bruggeman, Plasma Sources Science and Technology 27, 095006 (2018).

${ }^{24}$ S. Iseni, A. Schmidt-Bleker, J. Winter, K.-D. K.-D. Weltmann, and S. Reuter, Journal of Physics D: Applied Physics 47, 152001 (2014).

${ }^{25}$ G. B. Sretenović, P. S. Iskrenović, I. B. Krstić, V. V. Kovačević, B. M. Obradović, and M. M. Kuraica, Plasma Sources Science and Technology 27, 07LT01 (2018).

${ }^{26}$ G. B. Sretenović, I. B. Krstić, V. V. Kovačević, B. M. Obradović, and M. M. Kuraica, Applied Physics Letters 99, 161502 (2011).

${ }^{27}$ A. V. Pipa, Y. Z. Ionikh, V. M. Chekishev, M. Dünnbier, and S. Reuter, Applied Physics Letters 106, 244104 (2015).

${ }^{28}$ H. R. Griem, Principles of Plasma Spectroscopy, Cambridge Monographs on Plasma Physics No. 2 (Cambridge University Press, Cambridge, [Eng.] ; New York, 1997).

${ }^{29}$ S. Djurović and N. Konjević, Plasma Sources Science and Technology 18, 035011 (2009).

${ }^{30}$ Malvern A. R., Pinder A. C., Stacey D. N., Thompson R. C., and Kuhn Heinrich Gerhard, Proceedings of the Royal Society of London. A. Mathematical and Physical Sciences 371, 259 (1980).

${ }^{31}$ Full width at half maximum of a profile (Gaussian, Lorentzian

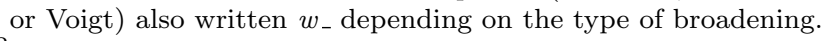

${ }^{32}$ P. J. Bruggeman, N. Sadeghi, D. C. Schram, and V. Linss, Plasma Sources Science and Technology 23, 023001 (2014).

${ }^{33}$ G. V. Naidis, Journal of Physics D: Applied Physics 44, 215203 (2011).

${ }^{34}$ N. Y. Babaeva, G. V. Naidis, V. A. Panov, R. Wang, Y. Zhao, and T. Shao, Physics of Plasmas 25, 063507 (2018).

${ }^{35}$ J. P. Boeuf, Y. Lagmich, T. Unfer, T. Callegari, and L. C. Pitchford, Journal of Physics D: Applied Physics 40, 652 (2007).

${ }^{36}$ S. Chen, R. G. W. van den Berg, and S. Nijdam, Plasma Sources Science and Technology 27, 055021 (2018). 
${ }^{37}$ P. Viegas, E. Slikboer, A. Obrusník, Z. Bonaventura, A. Sobota, E. Garcia-Caurel, O. Guaitella, and A. Bourdon, Plasma Sources
Science and Technology 27, 094002 (2018). 